\title{
Effects of cyclin $D_{1}$ gene amplification and protein expression on time to recurrence in postmenopausal breast cancer patients treated with anastrozole or tamoxifen: a TransATAC study
}

Katja Lundgren ${ }^{1,2}$, Matthew Brown ${ }^{2}$, Silvia Pineda ${ }^{3}$, Jack Cuzick ${ }^{3}$, Janine Salter ${ }^{4}$, Lila Zabaglo ${ }^{4}$, Anthony Howell $^{2}$, Mitch Dowsett ${ }^{4,5}$ and Göran Landberg ${ }^{2,6^{*}}$, for the TransATAC investigators

\begin{abstract}
Introduction: Gene amplification of CCND1 is observed in a subgroup of breast cancers with poor prognosis, whereas overexpression of the protein cyclin $D_{1}$ has been linked to both worse and better clinical outcome. CCND1 amplification and protein overexpression have also been associated with resistance to treatment with tamoxifen or even to a potentially detrimental effect of tamoxifen.
\end{abstract}

Methods: To clarify these challenging and partly contrasting treatment predictive and prognostic links for cyclin $D_{1}$ we analysed a large cohort of postmenopausal breast cancer patients randomised to receive either adjuvant anastrozole or tamoxifen, as part of the Arimidex, Tamoxifen, Alone or in Combination (ATAC) trial. The CCND1 amplification status and protein expression of cyclin $D_{1}$ were assessed by chromogenic in situ hybridisation and immunohistochemistry, respectively, in 1,155 postmenopausal, oestrogen-receptor-positive breast cancer patients included in the TransATAC substudy.

Results: Amplification of CCND1 was observed in $8.7 \%$ of the tumours and was associated with increased risk of disease recurrence (hazard ratio $=1.61 ; 95 \%$ confidence interval, 1.08 to 2.41 ) after adjustment for other clinicopathological parameters. In contrast, nuclear expression of cyclin $D_{1}$ protein was associated with decreased recurrence rate (hazard ratio $=0.6 ; 95 \%$ confidence interval, 0.39 to 0.92 ). The intensity of nuclear or cytoplasmic expression was not of prognostic value. There was no significant interaction between cyclin $\mathrm{D}_{1}$ status and treatment efficacy, ruling out any major detrimental effect of tamoxifen in CCND1-amplified postmenopausal breast cancer.

Conclusions: In summary, CCND1 amplification and low nuclear expression of cyclin $\mathrm{D}_{1}$ predicted poor clinical outcome in postmenopausal breast cancer patients treated with either anastrozole or tamoxifen.

Trial Registration: Current Controlled Trials ISRCTN18233230.

\section{Introduction}

Hormone dependence is a fundamental hallmark of the majority of breast cancers, and tumour growth can be inhibited either by deprivation of circulating oestrogens or by antagonising the effect of these hormones on their receptors [1]. The selective oestrogen receptor (ER)

\footnotetext{
* Correspondence: glandberg@picr.man.ac.uk

${ }^{2}$ Breakthrough Breast Cancer Research Unit, School of Cancer, Enabling Sciences and Technology, University of Manchester, Manchester Academic Health Science Centre Paterson Institute for Cancer Research, The Christie NHS Foundation Trust, Wilmslow Road, Manchester M20 4BX, UK Full list of author information is available at the end of the article
}

modulator tamoxifen has long been the most commonly used adjuvant therapy for patients with advanced hormone-sensitive breast cancer [2]. In recent years, however, aromatase inhibitors have become an alternative treatment option for postmenopausal women with breast cancer. An aromatase inhibitor acts by interfering with the enzyme that converts androgens to oestrogen, and reduces tumour and systemic oestrogen concentration [3]. The third-generation selective aromatase inhibitor anastrozole (Arimidex) reduces serum oestradiol to nanomolar concentrations [4]. The Arimidex, Tamoxifen, 
Alone or in Combination (ATAC) trial was designed to compare the efficacy of anastrozole alone or in combination with the established adjuvant treatment, tamoxifen for 5 years, as adjuvant treatment for postmenopausal women with operable breast cancer [5]. The study demonstrated that the efficacy of anastrozole was higher compared with tamoxifen alone, and also superior to the combination of both agents [5,6]. After a median followup of 10 years, 5 years after completion of treatment, the significant advantage for anastrozole over tamoxifen as initial adjuvant therapy for postmenopausal, ER-positive breast cancer patients was confirmed [7].

In breast cancer, genetic alterations such as amplifications and deletions occur within the tumour at high frequencies, and a number of these alterations are closely related to poor clinical outcome. One such region of amplification is $11 \mathrm{q} 13$, harbouring the cyclin $\mathrm{D}_{1}$ gene CCND1 [8-10]. Cyclin $\mathrm{D}_{1}$ plays a crucial role as a cell cycle regulator, promoting progression through the $\mathrm{G}_{1}-\mathrm{S}$ phase, following complex formation with CDK4/6 and phosphorylation of the retinoblastoma protein [11]. Various studies have described the oncogenic capacity of cyclin $\mathrm{D}_{1}$ in vitro, and overexpression in vivo results in tumour formation [12-14]. Overexpression of cyclin $D_{1}$ is observed in approximately $50 \%$ of breast cancers $[15,16]$, and cyclin $D_{1}$ is one of the most commonly overexpressed proteins in this form of cancer. A number of studies report cyclin $D_{1}$ overexpression to be a predictor of worse prognosis $[17,18]$, while others have found an association with an ER-positive phenotype and a better clinical outcome [19-23]. In about $15 \%$ of all primary breast cancers, overexpression is due to amplification of the corresponding gene CCND1 [15,24,25], and this specific amplification has been linked to poor prognosis $[23,26]$.

Despite the presence of $E R \alpha$, approximately $50 \%$ of breast cancers develop resistance to hormonal treatment, a major clinical limitation of breast cancer therapy $[27,28]$. The mechanisms behind this phenomenon have been extensively studied, and imply a complex signalling network governing ER function and interaction with various co-regulators [29-32]. Cyclin $\mathrm{D}_{1}$ is one such co-factor, known to interact with $\mathrm{ER} \alpha$ and, independently of oestrogen, activate the receptor and potentially modify oestrogen/anti-oestrogen responses [33,34]. Overexpression of cyclin $\mathrm{D}_{1}$ has been reported to result in a conformational change in ER $\alpha$ that induces receptor activation in the presence of the novel selective ER modulator arzoxifene, which in turn promotes growth of MCF-7 cells - indicating a change from antagonist to agonist [28]. This study also suggests that different mechanisms are required to confer resistance depending on the specific anti-oestrogen administered, and that changes in the conformation of ER $\alpha$ play a crucial role in anti-hormonal insensitivity. A similar study demonstrated that overexpression of cyclin $\mathrm{D}_{1}$ reversed the growth inhibitory effect of tamoxifen in two ER-positive breast cancer cell lines [35]. In line with these experimental findings we have previously observed that cyclin $\mathrm{D}_{1}$ overexpression was associated with tamoxifen resistance in premenopausal and postmenopausal breast cancer $[21,36]$. Worryingly, amplification of CCND1 was further linked to a potentially detrimental effect of tamoxifen in premenopausal breast cancer patients, when compared with randomised control patients not receiving any adjuvant therapy [36].

The aim of our study was to characterise the association between CCND1 amplification and cyclin $\mathrm{D}_{1}$ protein expression and breast cancer recurrence in a large randomised cohort of postmenopausal patients with ERpositive breast cancer treated with endocrine therapy. In addition, we aimed to assess whether there was a significant difference in response to anastrozole versus tamoxifen according to cyclin $\mathrm{D}_{1}$ gene and protein status, and thereby to address any potentially unfavourable effects of tamoxifen in subgroups of breast cancer defined by CCND1 amplification.

\section{Materials and methods Patients}

The ATAC trial originally evaluated the efficacy and safety of 5 years of anastrozole, tamoxifen, or the combination of both treatments in postmenopausal patients presenting with localised breast cancer [7]. For the TransATAC protocol, formalin-fixed, paraffin-embedded blocks of the primary tumour were collected from as many hormone-receptor-positive patients as possible, from the monotherapy trial arms [37]. The endpoint for the analyses was any breast cancer recurrence and the median follow-up time was 10 years. The original study was performed according to the Declaration of Helsinki after approval by an institutional review board and ethics committee, and informed consent was obtained from all patients enrolled in the study.

\section{Immunohistochemistry}

Nine tissue microarrays (TMAs) were used, each originally including from 165 to 200 tumour tissue samples from the patients included in the TransATAC study. This set of TMAs had one tissue core for each patient: a sample set was analysed for cyclin $\mathrm{D}_{1}$ protein expression and a set was analysed for CCND1 copy number. For detailed description of the TMA assembly we refer to our previously published study [37]. The TMA slides were deparaffinised, rehydrated and microwave-treated in target retrieval solution pH 9.9 (Dako, Glostrup, Denmark), and were processed in an automated immunostainer (Techmate 500; Dako, Copenhagen, Denmark) using the Envision software (Dako, Glostrup, Denmark). 
The antibody employed was a mouse monoclonal antibody reactive against human cyclin $\mathrm{D}_{1}(1: 100$, clone DSC-6; Dako, Glostrup, Denmark).

Staining of cyclin $\mathrm{D}_{1}$ was assessed as cytoplasmic staining intensity (0 to 2$)$ as well as nuclear staining intensity (0 to 3$)$ and fraction-positive nuclei $(0,<1 \%, 1$ to $9 \%, 10$ to $32 \%, 33$ to $67 \%$ and $>67 \%$ ) according to the Allred Score [38]. Evaluation was performed by two independent observers (one a pathologist), with the pathologist's score superseding the other observer's at consolidation. Conflicting observations were low $(<5 \%)$ for all evaluations made. All immunohistochemical evaluations were performed without knowledge of tumour characteristics. In cases of no evaluation, the tumour cores were either nonrepresentative (that is, no invasive tumour cells) or were missing. This study was carried out and is reported according to REMARK guidelines [39].

\section{Chromogenic in situ hybridisation}

Chromogenic in situ hybridisation (CISH) was performed according to the Zymed SPoT-Light Cyclin $\mathrm{D}_{1}$ Probe protocol suited for CISH [40] using the SPoT-Light Cyclin $\mathrm{D}_{1}$ Amplification Probe (Zymed Laboratories, Invitrogen Immunodetection, San Francisco, CA, USA). Pretreatment procedures included heating and enzyme digestion to optimise the CISH performance. Nonamplified cases were classified as 0 , cases with up to 8 copies classified as 1 and $>8$ copies classified as 2 . In statistical analyses, classifications 1 and 2 were both included in the subgroup defined as amplified.

\section{Statistical analyses}

The primary endpoint for the analyses was time to recurrence (TTR), also known as the recurrence-free interval. TTR was defined as the time from randomisation to first locoregional recurrence, distant recurrence or contralateral disease. Statistical analyses were performed according to a prespecified statistical analysis plan approved by the ATAC Steering Committee. Cox proportional hazards regression models were fitted to TTR, and hazard ratios (HRs) and associated 95\% confidence intervals (CIs) were estimated. The statistical tests employed for correlations between cyclin $D_{1}$ variables and clinicopathological parameters were the Armitage's trend test, the Wilcoxon test, the Goodman's test and the Cuzick test [41]. Multiple hypothesis testing was not corrected for, thus marginal $P$ values should be interpreted with caution. The contribution of cyclin $D_{1}$ protein expression was analysed by the change in likelihood ratio chi-squared test (one degree of freedom) univariately and multivariately, in addition to a model with tumour size, nodal status, grade (central) and Ki67 expression, for all patients and nonamplified patients. All hypothesis tests were conducted at the two-sided
$P=0.05$ level. For detailed description of statistical analyses, we refer to a previous report [42].

\section{Results}

Distribution of CCND1 amplification status and cyclin $\mathrm{D}_{1}$ protein staining categories

In the ATAC trial, 5,880 hormone-receptor-positive breast cancer patients were randomly assigned to receive the monotherapy anastrozole or tamoxifen. For the TransATAC protocol, 1,868 patients from the monotherapy arms were initially included. In the present study, 627 patients were not assessable for CCND1 amplification status due to missing or damaged tissue cores, and 86 patients were excluded as they did not meet the study criteria of being ER-positive, leaving 1,155 patients assessable for CCND1 amplification status. Out of the patients with known amplification status, 1,054 (91.3\%) exhibited nonamplified tumours and 101 (8.7\%) were amplified (Figure 1a). High cyclin $\mathrm{D}_{1}$ cytoplasmic intensity was observed in 380 tumours (32.9\%), high nuclear cyclin $\mathrm{D}_{1}$ intensity in 278 tumours (24.1\%), and 190 tumours (16.5\%) had $>67 \%$ nuclear fraction positivity as detailed in Additional file 1. CCND1 gene amplification was associated with a higher expression of nuclear cyclin $\mathrm{D}_{1}(P<$ $0.001)$ as well as a higher fraction of positive nuclei $(P<$ 0.001 ), but was not significantly correlated to the amount of cytoplasmic protein $(P=0.063)$ (Table 1 and Figure $1 b)$. Furthermore, positive correlations were observed between nuclear and cytoplasmic components of cyclin $\mathrm{D}_{1}$ protein expression.

\section{CCND1 gene amplification and patient prognosis}

Initially we studied the association between CCND1 amplification status and TTR. Survival plots showed that patients exhibiting CCND1-amplified tumours had an increased risk of recurrence compared with patients showing nonamplified tumours $(\mathrm{HR}=2.04 ; 95 \% \mathrm{CI}$, 1.37 to $3.03 ; \chi_{1}{ }^{2}=10.51 ; P<0.001$, univariate) (Figure $2 \mathrm{a})$. Even when adjusting for the effects of tumour size, nodal status, grade (central) and Ki67 expression, amplification of $C C N D 1$ was significantly associated with an increased risk of recurrence $(\mathrm{HR}=1.61 ; 95 \% \mathrm{CI}, 1.08$ to 2.41; $P=0.03)$ (Table 2).

\section{Cyclin $D_{1}$ protein expression and patient prognosis}

We next investigated how cyclin $\mathrm{D}_{1}$ protein localisation and expression was related to TTR. There was no significant difference in TTR with relation to cytoplasmic cyclin $\mathrm{D}_{1}$ (Figure $2 \mathrm{~b}$ ) or cyclin $\mathrm{D}_{1}$ nuclear intensity (Figure 2c and Table 2). Surprisingly, a greater fraction of cyclin $\mathrm{D}_{1}$-positive nuclei was associated with longer TTR (HR $=0.60 ; 95 \% \mathrm{CI}, 0.39$ to $0.92 ; P=0.03$ ) when adjusted for the effects of tumour size, nodal status, 


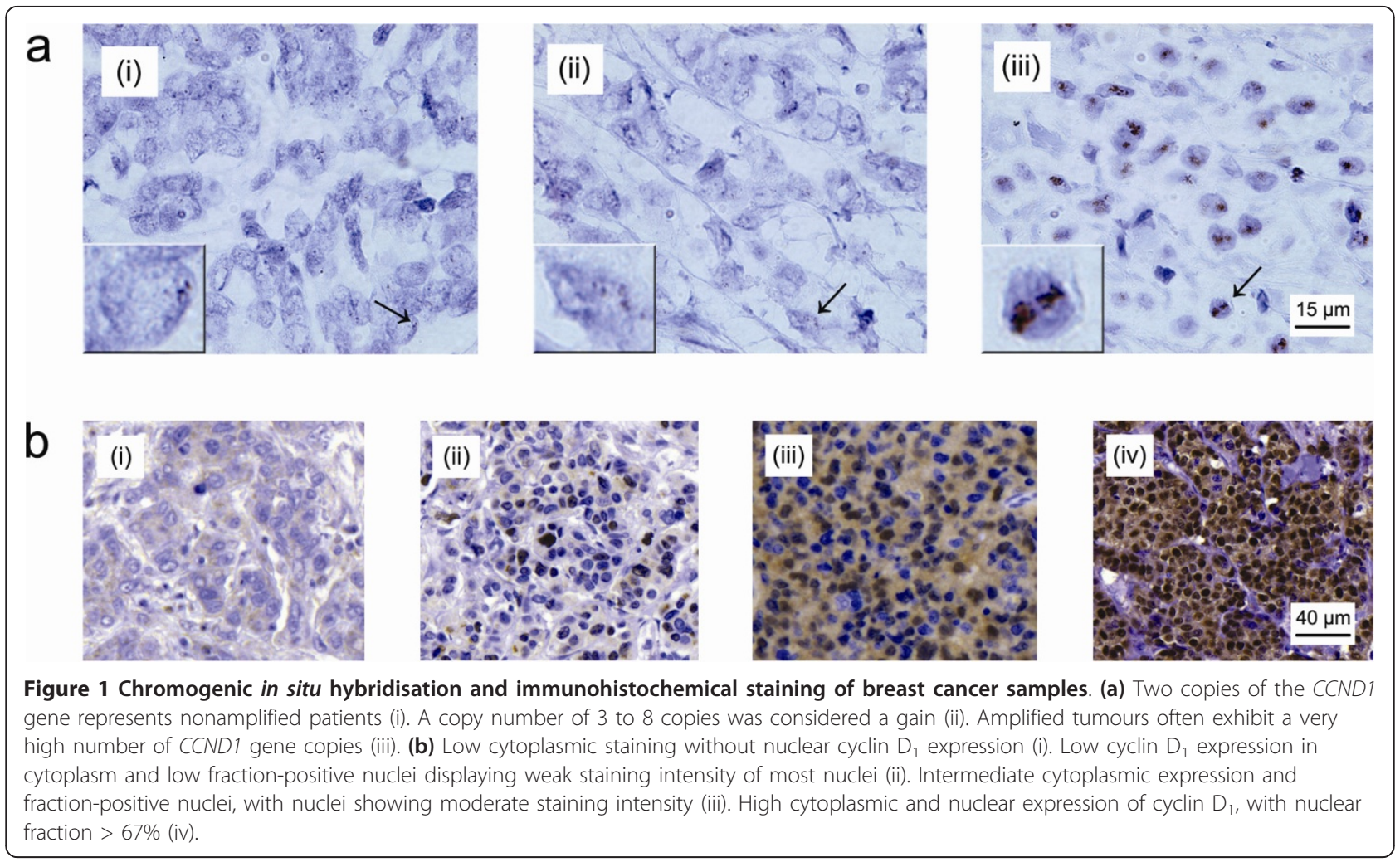

grade and Ki67 expression (Figures 2d, 3b and Table 2). Also, when subcategorising patients into high versus lower subgroups of cytoplasmic cyclin $\mathrm{D}_{1}$ there was a trend towards a significant difference in TTR $(P=$ 0.055 ; univariate, $\mathrm{HR}=0.71 ; 95 \% \mathrm{CI}, 0.51$ to $0.98 ; P=$ 0.039) (Figure 3a and Table 2). When focusing on the non-amplified breast cancer samples, high cytoplasmic cyclin $\mathrm{D}_{1}$ protein expression was indeed associated with a better outcome $(P=0.005)$ (Figure $3 \mathrm{c}$ and Table 2$)$. The data further indicated that the lowest fraction of cyclin $\mathrm{D}_{1}$-positive nuclei $(<1 \%)$ was associated with shorter TTR compared with subgroups of higher percentage positive nuclei, as illustrated in Figure 3b, d. Unfortunately, the number of CCND1-amplified cases was too low to analyse survival according to nuclear protein expression; that is, this subgroup contained no cases exhibiting a nuclear protein expression $<1 \%$.

\section{Interactions of cyclin $\mathrm{D}_{1}$ and treatment, nodal status and Ki67}

Based on previous reports indicating that amplification of the CCND1 gene and cyclin $\mathrm{D}_{1}$ overexpression might be associated with tamoxifen resistance or detrimental effects, we wanted to elucidate whether this could be further clarified in the patient cohort of the present study. The subgroup of patients treated with tamoxifen included 571 cases, and the anastrozole-treated subgroup included 584 patients. For CCND1 amplification status there was no significant difference in TTR between anastrozole-treated and tamoxifen-treated patients (Figure 4a). Moreover, for nonamplified cases there was no difference according to nodal status or Ki67 levels between the treatment arms. For cytoplasmic cyclin $\mathrm{D}_{1}$ expression there was an association in TTR according to amplification status (HR $=2.8$; 95\% CI, 1.2 to 6.4 for the interaction) (Figure 4b). In nonamplified breast cancers, however, no significant difference in TTR was observed for treatment $(\mathrm{HR}=1.8 ; 95 \% \mathrm{CI}, 0.8$ to 3.9 for the interaction), nodal status ( $\mathrm{HR}=1.5 ; 95 \% \mathrm{CI}, 0.7$ to 3.2 ) or Ki67 levels ( $\mathrm{HR}=1.3$; 95\% CI, 0.6 to 3.0 ) (Figure 4b). Finally, for the nuclear fraction we observed an association in Ki67 levels for TTR (HR $=3.5$; 95\% CI, 1.0 to 12.3 for the interaction) (Figure 4c).

\section{Cyclin $\mathrm{D}_{1}$, CCND1 and clinicopathological data}

The CCND1 amplification status was positively correlated to tumour grade $(P<0.001)$ and proliferation (defined as Ki67 expression) $(P<0.001)$, but not to nodal status or tumour size (Table 1). Cytoplasmic cyclin $\mathrm{D}_{1}$ expression was inversely correlated to tumour size (all patients; $P=0.01)$ and nodal status $(P=0.031)$, and was positively correlated to proliferation $(P=$ 0.021 ). Both nuclear staining intensity of cyclin $D_{1}$ and fraction-positive nuclei were associated with higher 
Table 1 Associations between CCND1 amplification status, cyclin $D_{1}$ protein expression and clinicopathological variables in all patients

\begin{tabular}{|c|c|c|c|c|c|c|c|}
\hline All patients & $\begin{array}{l}\text { Cyclin } \mathrm{D}_{1} \text { cytoplasmic intensity } \\
\text { (negative/low, intermediate, } \\
\text { high) }\end{array}$ & $\begin{array}{l}\text { Cyclin } \mathrm{D}_{1} \text { nuclear intensity } \\
\text { (negative/low, intermediate, } \\
\text { high) }\end{array}$ & $\begin{array}{l}\text { Cyclin } D_{1} \text { nuclear fraction }(<1 \%, 1 \\
\text { to } 9 \%, 10 \text { to } 32 \%, 33 \text { to } 67 \%,> \\
67 \%)\end{array}$ & $\begin{array}{l}\text { Tumour grade } \\
\text { (well, moderate, } \\
\text { poor) }\end{array}$ & $\begin{array}{l}\text { Tumour size }{ }^{a} \\
(\mathrm{~mm})\end{array}$ & $\begin{array}{l}\text { Nodal status } \\
\text { (negative, } 1 \text { to } \\
3,>3 \text { ) }\end{array}$ & Ki67 ${ }^{\mathrm{a}}$ \\
\hline \multicolumn{8}{|l|}{ CCND1 amplification } \\
\hline Nonamplified & $12 \%, 52 \%, 36 \%$ & $40 \%, 36 \%, 24 \%$ & $10 \%, 24 \%, 27 \%, 24 \%, 15 \%$ & $23 \%, 61 \%, 16 \%$ & 18.0 & $70 \%, 23 \%, 7 \%$ & 4.0 \\
\hline \multirow[t]{2}{*}{ Amplified } & $6 \%, 48 \%, 46 \%$ & $9 \%, 35 \%, 56 \%$ & $0 \%, 6 \%, 18 \%, 32 \%, 44 \%$ & $9 \%, 62 \%, 29 \%$ & 19.0 & $64 \%, 26 \%, 10 \%$ & 7.5 \\
\hline & Armitage $(P=0.063)$ & Armitage $(P<0.001)$ & Armitage $(P<0.001)$ & $\begin{array}{l}\text { Armitage }(P< \\
0.001)\end{array}$ & $\begin{array}{l}\text { Wilcoxon ( } P= \\
0.083 \text { ) }\end{array}$ & $\begin{array}{l}\text { Armitage ( } P= \\
0.341)\end{array}$ & $\begin{array}{l}\text { Wilcoxon }(P< \\
0.001)\end{array}$ \\
\hline \multicolumn{8}{|c|}{ Cyclin $D_{1}$ cytoplasmic intensity } \\
\hline \multicolumn{2}{|c|}{ Negative/low } & $74 \%, 16 \%, 10 \%$ & $23 \%, 33 \%, 26 \%, 11 \%, 4 \%$ & $26 \%, 59 \%, 15 \%$ & 17.5 & $68 \%, 24 \%, 8 \%$ & 3.2 \\
\hline \multicolumn{2}{|l|}{ Intermediate } & $40 \%, 36 \%, 24 \%$ & $10 \%, 24 \%, 27 \%, 25 \%, 14 \%$ & $17 \%, 63 \%, 20 \%$ & 19.0 & $64 \%, 34 \%, 2 \%$ & 4.6 \\
\hline \multirow{2}{*}{\multicolumn{2}{|c|}{ High }} & $20 \%, 43 \%, 37 \%$ & $3 \%, 16 \%, 25 \%, 28 \%, 28 \%$ & $23 \%, 61 \%, 16 \%$ & 17.0 & $74 \%, 20 \%, 6 \%$ & 5.6 \\
\hline & & Goodman $=0.44(P<0.001)$ & Goodman $=0.39(P<0.001)$ & $\begin{array}{l}\text { Goodman }=-0.06 \\
(P=0.238)\end{array}$ & $\begin{array}{l}\text { Cuzick trend } \\
(P=0.010)\end{array}$ & $\begin{array}{l}\text { Goodman }=-0.12 \\
(P=0.031)\end{array}$ & $\begin{array}{l}\text { Cuzick trend } \\
(P=0.021)\end{array}$ \\
\hline \multicolumn{8}{|c|}{ Cyclin $D_{1}$ nuclear intensity } \\
\hline \multicolumn{2}{|c|}{ Negative/low } & & $23 \%, 33 \%, 26 \%, 11 \%, 4 \%$ & $24 \%, 62 \%, 14 \%$ & 18.0 & $67 \%, 25 \%, 8 \%$ & 2.9 \\
\hline \multicolumn{2}{|l|}{ Intermediate } & & $1 \%, 12 \%, 41 \%, 36 \%, 10 \%$ & $18 \%, 65 \%, 17 \%$ & 18.0 & $68 \%, 25 \%, 7 \%$ & 4.8 \\
\hline \multirow[t]{2}{*}{ High } & & & $0 \%, 1 \%, 7 \%, 37 \%, 55 \%$ & $17 \%, 59 \%, 24 \%$ & 17.5 & $71 \%, 22 \%, 7 \%$ & 6.3 \\
\hline & & & Goodman $=0.88(P<0.001)$ & $\begin{array}{l}\text { Goodman }=0.16 \\
(P<0.001)\end{array}$ & $\begin{array}{l}\text { Cuzick trend } \\
(P=0.553)\end{array}$ & $\begin{array}{l}\text { Goodman }=-0.05 \\
(P=0.327)\end{array}$ & $\begin{array}{l}\text { Cuzick trend } \\
(P<0.001)\end{array}$ \\
\hline \multicolumn{8}{|c|}{ Cyclin $D_{1}$ nuclear fraction } \\
\hline \multicolumn{2}{|c|}{$<1 \%$} & & & $18 \%, 68 \%, 14 \%$ & 20.0 & $2 \%, 29 \%, 9 \%$ & 2.8 \\
\hline \multicolumn{2}{|l|}{1 to $9 \%$} & & & $23 \%, 62 \%, 15 \%$ & 18.0 & $68 \%, 25 \%, 7 \%$ & 2.7 \\
\hline \multicolumn{2}{|l|}{10 to $32 \%$} & & & $24 \%, 59 \%, 17 \%$ & 18.0 & $71 \%, 25 \%, 4 \%$ & 4.4 \\
\hline \multicolumn{2}{|l|}{33 to $67 \%$} & & & $20 \%, 59 \%, 21 \%$ & 18.0 & $70 \%, 21 \%, 9 \%$ & 4.9 \\
\hline \multirow[t]{2}{*}{$>67 \%$} & & & & $12 \%, 68 \%, 20 \%$ & 16.0 & $68 \%, 24 \%, 8 \%$ & 5.9 \\
\hline & & & & $\begin{array}{l}\text { Cuzick trend }(P= \\
0.005)\end{array}$ & $\begin{array}{l}\text { Spearman } \rho= \\
-0.04(P= \\
0.162)\end{array}$ & $\begin{array}{l}\text { Cuzick trend }(P= \\
0.694)\end{array}$ & $\begin{array}{l}\text { Spearman } \rho \\
=0.22(P< \\
0.001\end{array}$ \\
\hline
\end{tabular}

Tests used: Armitage's trend test, Wilcoxon test, Goodman's test, Spearman correlation test and Cuzick test. ${ }^{a}$ Median value for each category. 


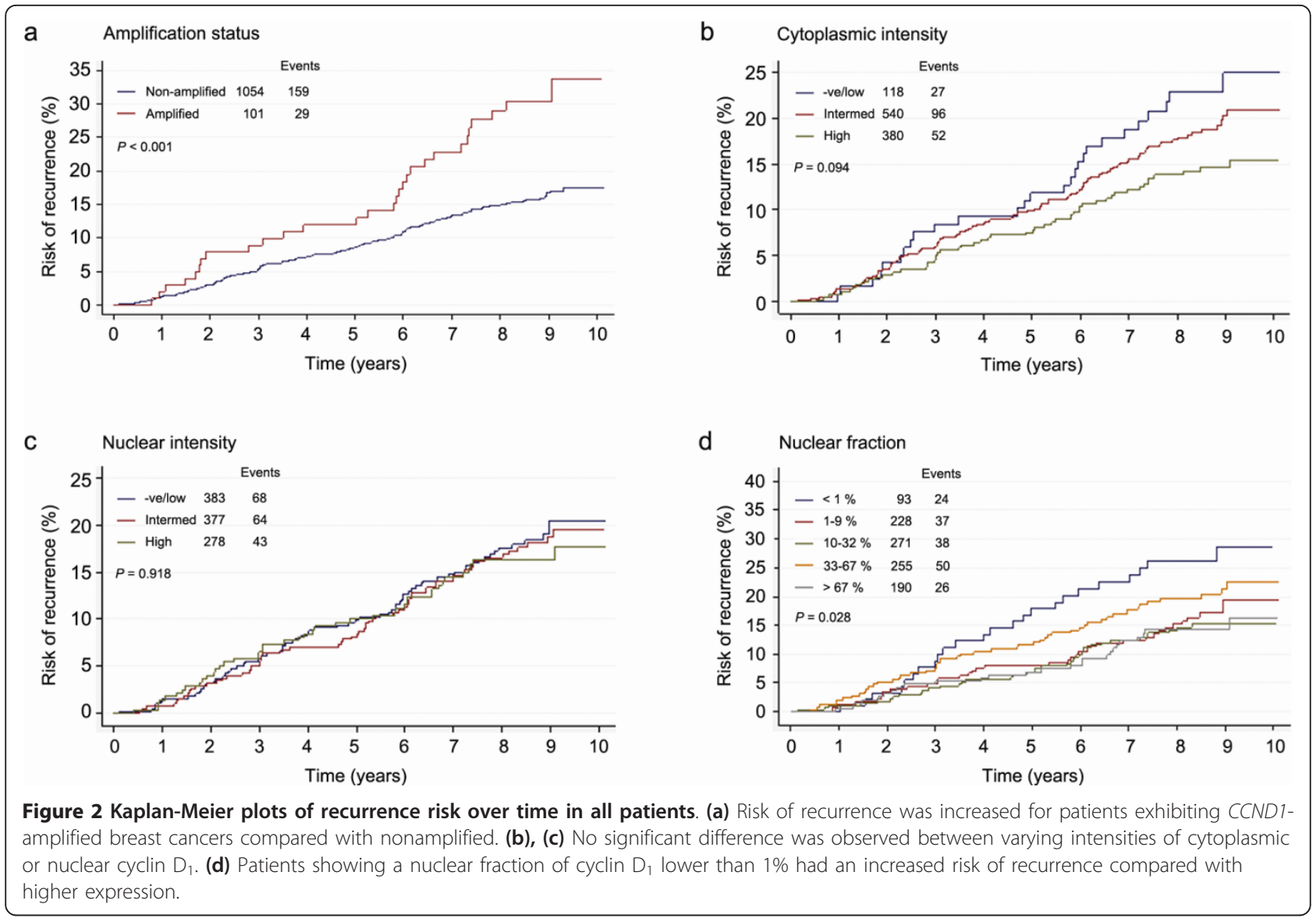

grade $(P<0.001$ and $P=0.005$ respectively) and higher proliferation rate (both $P<0.001$ ).

\section{Cyclin $D_{1}$, proliferation and time to recurrence}

Ki67 expression is a common marker used to analyse the proliferation rate in tumour samples, and high proliferation is linked to a more aggressive tumour phenotype. Surprisingly, despite a positive correlation between nuclear cyclin $\mathrm{D}_{1}$ expression and Ki67 expression (Table 1 and
Figure $5 \mathrm{a}$ ), high expression of nuclear cyclin $\mathrm{D}_{1}$ was associated with an improved TTR compared with low expression. To further illustrate how a combined proliferation and cyclin $\mathrm{D}_{1}$ assessment would be linked to TTR we subdivided patients according to Ki67 expression and nuclear cyclin $\mathrm{D}_{1}$ status. Patients with tumours exhibiting low Ki67 expression in association with 1 to $100 \%$ cyclin $\mathrm{D}_{1}$ positive nuclei (high) were associated with a considerably lower risk of recurrence $(P<0.001)$ (Figure $5 \mathrm{~b})$ compared

Table 2 Cox proportional Hazards models for estimating the effect on time to recurrence

\begin{tabular}{|c|c|c|c|c|c|c|}
\hline & \multicolumn{3}{|l|}{ Univariate } & \multicolumn{3}{|l|}{ Multivariate } \\
\hline & $\mathrm{HR}(95 \% \mathrm{Cl})$ & $\chi_{1}^{2}$ & $P$ value & HR $(95 \% \mathrm{Cl})$ & $\chi_{1}^{2}$ & $P$ value \\
\hline \multicolumn{7}{|l|}{ All patients } \\
\hline CCND1, amplified vs. nonamplified & 2.04 (1.37 to 3.03$)$ & 10.51 & $<0.001$ & 1.61 (1.08 to 2.41$)$ & 4.86 & 0.030 \\
\hline Cyclin $D_{1}$ cytoplasmic intensity, high vs. remainder & 0.71 (0.51 to 0.98$)$ & 4.43 & 0.039 & $0.78(0.56$ to 1.09$)$ & 2.15 & 0.143 \\
\hline Cyclin $D_{1}$ nuclear intensity, high vs. remainder & 0.91 (0.64 to 1.28$)$ & 0.30 & 0.588 & $0.85(0.59$ to 1.21$)$ & 0.84 & 0.360 \\
\hline Cyclin $D_{1}$ nuclear fraction, 1 to $100 \%$ vs. $<1 \%$ & $0.58(0.38$ to 0.90$)$ & 5.28 & 0.014 & $0.60(0.39$ to 0.92$)$ & 4.75 & 0.030 \\
\hline \multicolumn{7}{|l|}{ Nonamplified patients } \\
\hline Cyclin $D_{1}$ cytoplasmic intensity, high vs. remainder & 0.57 (0.39 to 0.82$)$ & 9.57 & 0.003 & 0.64 (0.44 to 0.95$)$ & 5.21 & 0.022 \\
\hline Cyclin $D_{1}$ nuclear intensity, high vs. remainder & $0.88(0.60$ to 1.32$)$ & 0.38 & 0.545 & $0.84(0.55$ to 1.26$)$ & 0.76 & 0.382 \\
\hline Cyclin $D_{1}$ nuclear fraction, 1 to $100 \%$ vs. $<1 \%$ & 0.52 (0.34 to 0.81$)$ & 7.29 & 0.004 & $0.54(0.35$ to 0.85$)$ & 6.36 & 0.012 \\
\hline
\end{tabular}

The $\chi_{1}{ }^{2}$ value is based on the likelihood ratio test with the associated $P$ values. Multivariate analyses were adjusted for tumour grade, tumour size, nodal status and $\mathrm{Ki67} . \mathrm{Cl}$, confidence interval; $\mathrm{HR}$, hazard ratio. 


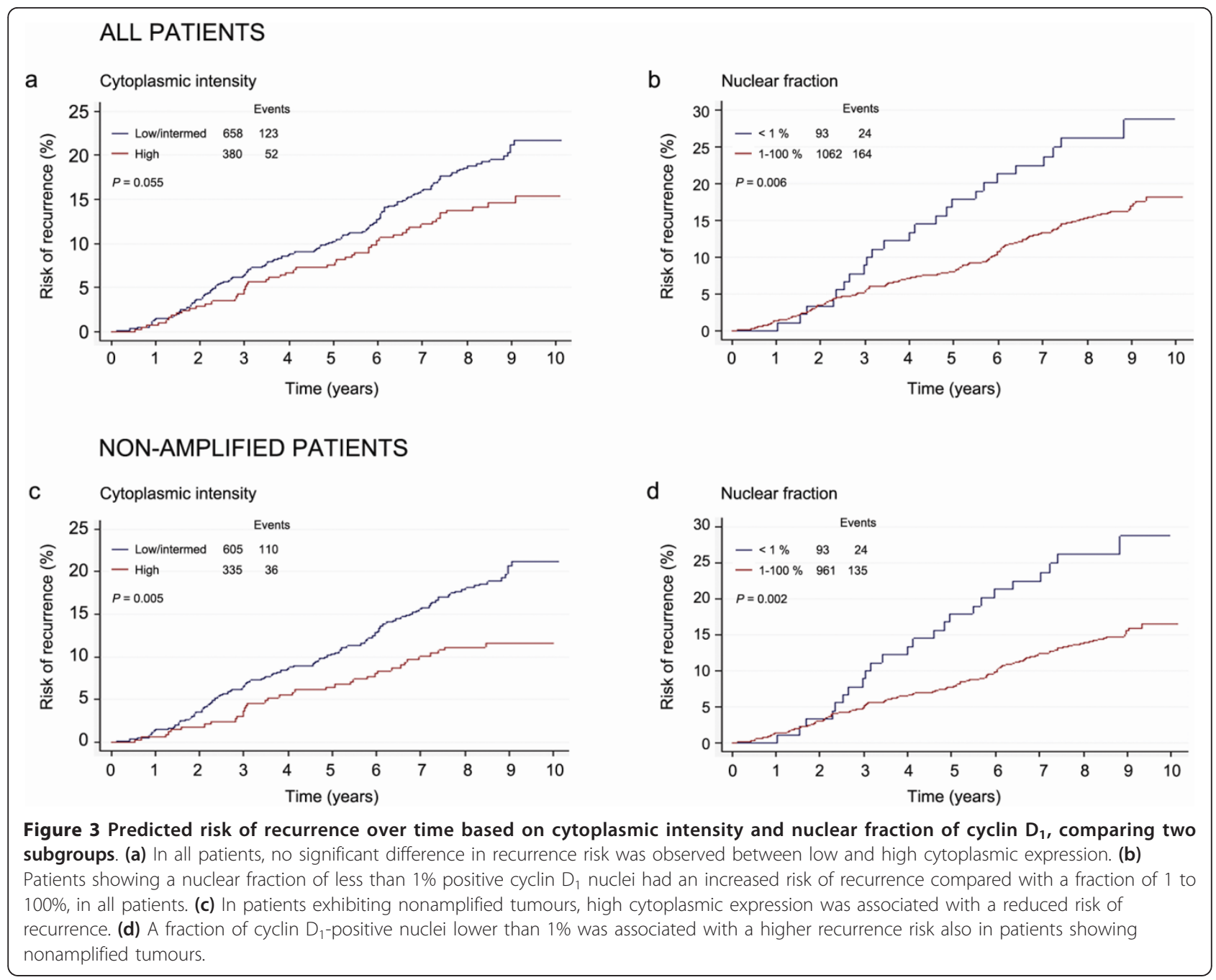

with the other subgroups. The subgroups of low cyclin $D_{1}$ include quite low patient numbers and hence the results should be interpreted with caution, but these results suggest that the expression of cyclin $D_{1}$ affects disease outcome independently of proliferation status.

\section{Discussion}

Amplification of the CCND1 gene has been associated with a poor patient outcome in previous studies $[19,26]$, whilst controversy regarding overexpression of cyclin $D_{1}$ protein in relation to patient survival still exists. Cyclin $D_{1}$ has been reported to be a prognostic marker in invasive breast cancer and has been associated with both a less aggressive ER-positive phenotype [20,22] and also with an adverse clinical outcome [18]. These conflicting findings can potentially be explained by the low patient numbers analysed and/or methodological discrepancies. To clarify the importance of cyclin $D_{1}$ in breast cancer we therefore analysed the expression of cyclin $\mathrm{D}_{1}$ in different subcellular localisations, using a previously validated antibody [36], as well as the gene amplification status by the well-established CISH technique in a large, well-characterised randomised patient cohort including more than 1,000 patients with ER-positive breast cancers. Our data support studies indicating that low cyclin $\mathrm{D}_{1}$ protein expression as well as CCND1 amplification are linked to tumour aggressiveness and increased risk of disease recurrence in ERpositive postmenopausal breast cancer $[23,26]$. Similar findings have been observed for HER2, where both high expression linked to amplification and low expression are linked to poor outcome [43].

Amplification of CCND1 was observed in $8.7 \%$ of the tumours, which is slightly lower than the frequency of 10 to $15 \%$ generally reported, even though some groups have demonstrated a lower percentage of CCND1-amplified tumours $[15,44,45]$. The slightly lower fraction of CCND1-amplified cases may be due to all patients being ER-positive or due to methodological differences and different cutoff points for defining amplification between studies. In addition, the use of TMAs has certain 
a

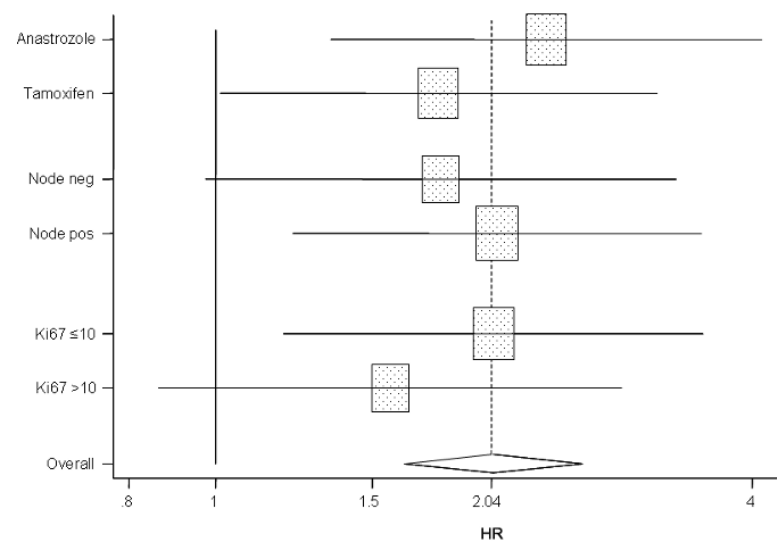

Cytoplasmic intensity (High vs. Low/intermed.)

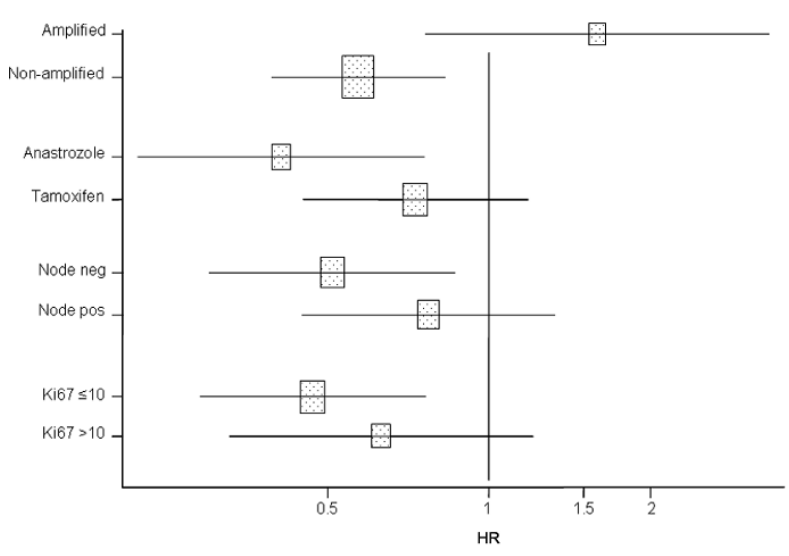

c

Nuclear fraction $(1-100 \%$ vs. $<1 \%)$

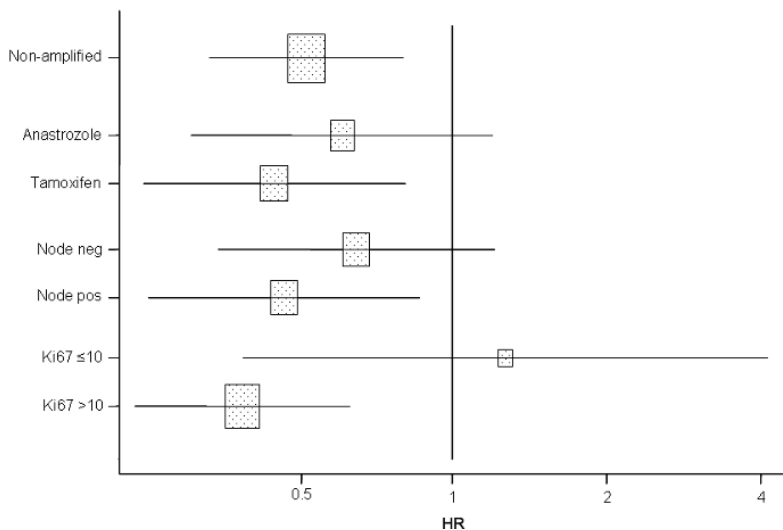

Figure 4 Forest plot showing the effect of CCND1 amplification, cytoplasmic and nuclear cyclin $\mathrm{D}_{1}$ expression. (a) Amplified against nonamplified breast cancers in the subgroups of treatment, nodal status and Ki67. (b) High cytoplasmic intensity against low or intermediate intensity. (c) Nuclear fraction of 1 to $100 \%$ against < 1\% positive nuclei. Reference population for all subgroups was nonamplified patients (except for amplification status). HR, hazard ratio; neg, negative; pos, positive. 
a

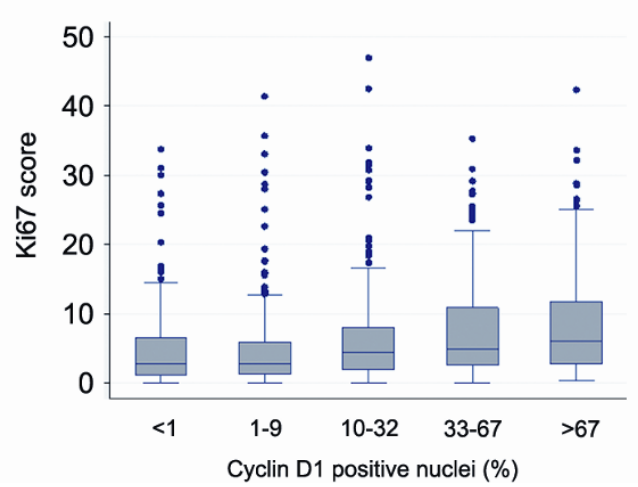

b

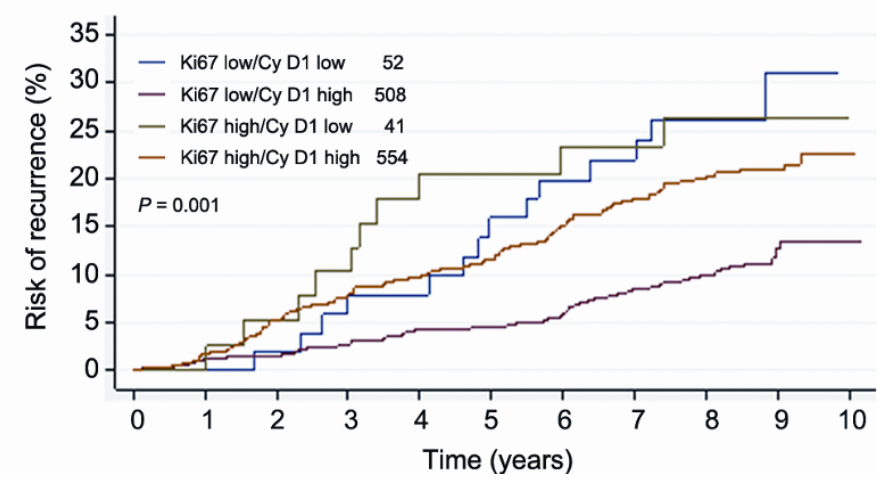

Figure 5 Recurrence risk over time based on the expression of Ki67 and cyclin $\mathbf{D}_{1}$. (a) Expression of Ki67 increased with increasing percentage of cyclin $D_{1}$-positive nuclei in the breast tumours. (b) Kaplan-Meier plot showing that the combination of high Ki67 and low cyclin $D_{1}$ expression was associated with high risk of recurrence (green). Patients exhibiting a high fraction of cyclin $\mathrm{D}_{1}$-positive tumour cell nuclei in concurrence with low Ki67 expression showed the lowest risk of recurrence (red).

limitations; however, this technique is indispensable when analysing large patient materials and is today a well-accepted approach for large-scale tumour sample analysis. In agreement with previous studies, gene amplification of CCND1 was associated with an overall adverse clinical outcome. The observed positive correlation between nuclear cyclin $\mathrm{D}_{1}$ expression and tumour grade and proliferation suggests a link between cyclin $D_{1}$ and aggressive disease. In contrast, both higher nuclear expression and high cytoplasmic expression of cyclin $\mathrm{D}_{1}$ was instead associated with a decreased recurrence risk. Despite a positive association between cyclin $D_{1}$ protein and CCND1 amplification status, both low nuclear fraction of cyclin $\mathrm{D}_{1}$ and $C C N D 1$ amplification were linked to earlier disease recurrence independently of other clinicopathological parameters - hence both factors serve as prognostic markers in endocrine-treated, ER-positive postmenopausal breast cancer. In patients not displaying CCND1 amplification, cytoplasmic expression of cyclin $\mathrm{D}_{1}$ was also an independent marker for longer TTR, indicating that the true prognostic value of cyclin $D_{1}$ protein expression may be obscured by the CCND1-amplified cases: the clinicopathological significance of cyclin $\mathrm{D}_{1}$ expression might thus be best considered separately for amplified and nonamplified cases.

Apart from the role as a prognostic marker, cyclin $D_{1}$ has been proposed as a predictive factor for tamoxifen response, as illustrated by poor clinical outcome in patients with ER-positive tumours with high cyclin $D_{1}$ expression treated with tamoxifen [46]. These findings together with numerous experimental reports [33-35] support that cyclin $\mathrm{D}_{1}$ overexpression might abrogate the response to tamoxifen, as previously reported by our group and others $[21,46]$. Our earlier discoveries have nevertheless been made in cohorts where patients were randomly assigned to receive either no adjuvant treatment or to receive tamoxifen $[21,36]$. In the present study we compared the two endocrine therapies anastrozole and tamoxifen in relation to disease recurrence and cyclin $\mathrm{D}_{1}$ status, but there were no untreated control patients. There was no significant difference in treatment response between these two adjuvant therapies by stratification for cyclin $D_{1}$ status, indicating that cyclin $D_{1}$ is not a predictive marker for differences in response to anastrozole versus tamoxifen. No conclusions can be drawn, however, regarding cyclin $\mathrm{D}_{1}$ as a marker for general endocrine treatment resistance, since no untreated patients were available for analysis within the TransATAC study. Moreover, differences in tamoxifen response in relation to cyclin $D_{1}$ in postmenopausal versus premenopausal breast cancer might exist. Our previous study reporting a potential unfavourable effect of tamoxifen included premenopausal patients exclusively, whereas this study focused exclusively on postmenopausal breast cancer cases and has shown no detrimental effect since the results for the two endocrine therapies were similar.

The relationship between cyclin $\mathrm{D}_{1}$, proliferation and prognosis is quite complex, with a positive correlation between cyclin $\mathrm{D}_{1}$ and Ki67 - Ki67 is associated with shorter TTR, while cyclin $\mathrm{D}_{1}$ is associated with longer TTR. Patients showing low expression of Ki67 had a longer TTR with the highest levels of cyclin $\mathrm{D}_{1}$ expression, whereas patients exhibiting higher levels of Ki67 had the shortest TTR with the lowest levels of cyclin $D_{1}$ expression. Multivariate analysis identified the fraction cyclin $\mathrm{D}_{1}$-positive nuclei as a predictor of outcome independently of other clinicopathological parameters such as Ki67. These results suggest that, irrespective of proliferation status, intermediate to high expression of cyclin $\mathrm{D}_{1}$ 
results in a prolonged TTR in ER-positive, postmenopausal breast cancer patients. Similar results were observed in our previous study of randomised material from premenopausal breast cancer patients [47]. The relationship between cyclin $\mathrm{D}_{1}$, proliferation and prognosis hence seems to be complex, and this could in part be explained by potential additional functions for cyclin $\mathrm{D}_{1}$ unrelated to proliferation control, as well as co-amplification and co-deletion of specific genes on chromosome 11q13, the locus harbouring CCND1.

\section{Conclusions}

This study confirms that the cyclin $\mathrm{D}_{1}$ status provides independent prognostic information regarding ER-positive, postmenopausal breast cancers, supporting its emerging role as a biomarker that might be useful in the clinic. Our results demonstrate that high expression of cyclin $\mathrm{D}_{1}$ was associated with a reduced risk of recurrences, whereas amplification of the CCND1 gene was linked to an aggressive disease. Finally, no difference in response to anastrozole compared with tamoxifen was observed according to expression of cyclin $\mathrm{D}_{1}$ gene amplification or protein expression.

\section{Additional material}

Additional file 1: Supplementary Table 1showing the distribution of cyclin $D_{1}$ staining categories.

\section{Abbreviations}

ATAC: Arimidex, Tamoxifen, Alone or in Combination; Cl: confidence interval; CISH: chromogenic in situ hybridisation; ER: oestrogen receptor; HR: hazard ratio; TMA: tissue microarray; TTR: time to recurrence.

\section{Acknowledgements \\ The authors thank Elise Nilsson for excellent technical implementation. This study was supported by grants from the Swedish Cancer Society, the Swedish Research Council, the Knut and Alice Wallenberg Foundation, Malmö University Hospital Research and Cancer Funds, Lund University Research Funds, South Swedish and South-East Swedish Breast Cancer groups and Breakthrough Breast Cancer Unit, Manchester, UK.}

\section{Author details \\ 'Center for Molecular Pathology, Department of Laboratory Medicine, Lund University, Malmö University Hospital, SE-205 02 Malmö, Sweden. ${ }^{2}$ Breakthrough Breast Cancer Research Unit, School of Cancer, Enabling Sciences and Technology, University of Manchester, Manchester Academic Health Science Centre Paterson Institute for Cancer Research, The Christie NHS Foundation Trust, Wilmslow Road, Manchester M20 4BX, UK. ${ }^{3}$ Cancer Research UK Centre for Epidemiology, Mathematics and Statistics, Queen Mary University of London, Wolfson Institute of Preventive Medicine, London EC1M 6BQ, UK. ${ }^{4}$ Breakthrough Breast Cancer Research Centre, Institute of Cancer Research, 237 Fulham Road, London SW3 6JB, UK. ${ }^{5}$ Royal Marsden Hospital, 237 Fulham Road, London SW3 6JJ, UK. ${ }^{6}$ Sahlgrenska Cancer Center, University of Gothenburg, 40530 Göteborg, Sweden.}

\section{Authors' contributions}

$\mathrm{KL}$ carried out the immunohistochemical and CISH assessments, participated in the study design and drafted the manuscript. MB assisted with evaluation of the immunohistochemistry. SP performed the statistical analyses. JC designed the clinical trial, assembled trial data, and planned and performed the statistical analyses. JS assembled trial data. LZ assembled trial data. AH designed the clinical trial and collected clinical data. MD designed the clinical trial and collected clinical data, and initiated and conceived the current study. GL initiated and conceived the study, supervised interpretation of the data, took part in the immunohistochemical assessments and evaluation of $\mathrm{CISH}$, and helped to draft the manuscript. All authors took part in data interpretation, writing the report and approval of the final version of the manuscript.

\section{Competing interests}

JC has acted as a consultant and/or on advisory boards for AstraZeneca and received commercial research grants from AstraZeneca. AH has acted as a consultant and/or on advisory boards for AstraZeneca, GSK, Pfizer, Roche and Amgen, and has received honoraria from AstraZeneca. MD receives paid advisory boards and research funding from each of Novartis, AstraZeneca and Roche. The remaining authors declare that they have no competing interests.

Received: 5 August 2011 Revised: 18 January 2012

Accepted: 4 April 2012 Published: 4 April 2012

\section{References}

1. Howell A, Dowsett M: Recent advances in endocrine therapy of breast cancer. BMJ 1997, 315:863-866.

2. Yoshida M, Haybittle JL, Davies C, Mason BH, Wilcken N, Ploner M Yosef HMA, Lobelle JP, Peek U, Powell J, Mauriac L, Piccart MJ, Price JJ, Hupperets PSGJ, Ragaz J, Weiss RB, Abu-Zahra HT, Portnoj SM, Riley D, Gordon NH, Davis HL, Naja A, Romestaing P, Dubois JB, Mace-Lesec'h J, Rambert P, Barkmanova J, Owen JR, Meier P, Swindell R: Effects of chemotherapy and hormonal therapy for early breast cancer on recurrence and 15-year survival: an overview of the randomised trials. Lancet 2005, 365:1687-1717.

3. Brodie AM, Njar VC: Aromatase inhibitors in advanced breast cancer: mechanism of action and clinical implications. J Steroid Biochem Mol Biol 1998, 66:1-10.

4. Geisler J, King N, Dowsett M, Ottestad L, Lundgren S, Walton P, Kormeset PO, Lonning PE: Influence of anastrozole (Arimidex), a selective, non-steroidal aromatase inhibitor, on in vivo aromatisation and plasma oestrogen levels in postmenopausal women with breast cancer. $\mathrm{Br} J$ Cancer 1996, 74:1286-1291.

5. Baum M, Budzar AU, Cuzick J, Forbes J, Houghton JH, Klijn JG, Sahmoud T: Anastrozole alone or in combination with tamoxifen versus tamoxifen alone for adjuvant treatment of postmenopausal women with early breast cancer: first results of the ATAC randomised trial. Lancet 2002, 359:2131-2139.

6. Howell A, Cuzick J, Baum M, Buzdar A, Dowsett M, Forbes JF, HoctinBoes G, Houghton J, Locker GY, Tobias JS: Results of the ATAC (Arimidex, Tamoxifen, Alone or in Combination) trial after completion of 5 years' adjuvant treatment for breast cancer. Lancet 2005, 365:60-62.

7. Cuzick J, Sestak I, Baum M, Buzdar A, Howell A, Dowsett M, Forbes JF: Effect of anastrozole and tamoxifen as adjuvant treatment for earlystage breast cancer: 10-year analysis of the ATAC trial. Lancet Oncol 2010, 11:1135-1141.

8. Ormandy CJ, Musgrove EA, Hui R, Daly RJ, Sutherland RL: Cyclin D, EMS1 and 11 q13 amplification in breast cancer. Breast Cancer Res Treat 2003 78:323-335.

9. Hui R, Ball JR, Macmillan RD, Kenny FS, Prall OW, Campbell DH, Cornish AL, McClelland RA, Daly RJ, Forbes JF, Musgrove EA, Robertson JF, Nicholson RI, Sutherland RL: EMS1 gene expression in primary breast cancer: relationship to cyclin $D_{1}$ and oestrogen receptor expression and patient survival. Oncogene 1998, 17:1053-1059.

10. Brown LA, Johnson K, Leung S, Bismar TA, Benitez J, Foulkes WD, Huntsman DG: Co-amplification of CCND1 and EMSY is associated with an adverse outcome in ER-positive tamoxifen-treated breast cancers. Breast Cancer Res Treat 2010, 121:347-54.

11. Sherr CJ, Roberts JM: CDK inhibitors: positive and negative regulators of $\mathrm{G}_{1}$-phase progression. Genes Dev 1999, 13:1501-1512.

12. Jiang W, Kahn SM, Zhou P, Zhang YJ, Cacace AM, Infante AS, Doi S, Santella RM, Weinstein IB: Overexpression of cyclin $D_{1}$ in rat fibroblasts 
causes abnormalities in growth control, cell cycle progression and gene expression. Oncogene 1993, 8:3447-3457.

13. Zhou P, Jiang W, Zhang YJ, Kahn SM, Schieren I, Santella RM, Weinstein IB Antisense to cyclin $D_{1}$ inhibits growth and reverses the transformed phenotype of human esophageal cancer cells. Oncogene 1995, 11:571-580.

14. Wang TC, Cardiff RD, Zukerberg L, Lees E, Arnold A, Schmidt EV: Mammary hyperplasia and carcinoma in MMTV-cyclin $D_{1}$ transgenic mice. Nature 1994, 369:669-671.

15. Gillett C, Fantl V, Smith R, Fisher C, Bartek J, Dickson C, Barnes D, Peters G: Amplification and overexpression of cyclin $D_{1}$ in breast cancer detected by immunohistochemical staining. Cancer Res 1994, 54:1812-1817.

16. Bartkova J, Lukas J, Muller H, Lutzhoft D, Strauss M, Bartek J: Cyclin $D_{1}$ protein expression and function in human breast cancer. Int $J$ Cancer 1994, 57:353-361.

17. Mclntosh GG, Anderson JJ, Milton I, Steward M, Parr AH, Thomas MD, Henry JA, Angus B, Lennard TW, Horne CH: Determination of the prognostic value of cyclin $D_{1}$ overexpression in breast cancer. Oncogene 1995, 11:885-891.

18. Kenny FS, Hui R, Musgrove EA, Gee JM, Blamey RW, Nicholson Rl, Sutherland RL, Robertson JF: Overexpression of cyclin $\mathrm{D}_{1}$ messenger RNA predicts for poor prognosis in estrogen receptor-positive breast cancer. Clin Cancer Res 1999, 5:2069-2076.

19. Michalides $R$, Hageman $P$, van Tinteren $H$, Houben L, Wientjens $E$, Klompmaker R, Peterse J: A clinicopathological study on overexpression of cyclin $D_{1}$ and of p53 in a series of 248 patients with operable breast cancer. Br J Cancer 1996, 73:728-734.

20. Gillett C, Smith P, Gregory W, Richards M, Millis R, Peters G, Barnes D: Cyclin $D_{1}$ and prognosis in human breast cancer. Int J Cancer 1996, 69:92-99.

21. Stendahl M, Kronblad A, Ryden L, Emdin S, Bengtsson NO, Landberg G: Cyclin $D_{1}$ overexpression is a negative predictive factor for tamoxifen response in postmenopausal breast cancer patients. Br J Cancer 2004, 90:1942-1948.

22. Hwang TS, Han HS, Hong YC, Lee HJ, Paik NS: Prognostic value of combined analysis of cyclin $D_{1}$ and estrogen receptor status in breast cancer patients. Pathol Int 2003, 53:74-80.

23. Naidu R, Wahab NA, Yadav MM, Kutty MK: Expression and amplification of cyclin $D_{1}$ in primary breast carcinomas: relationship with histopathological types and clinico-pathological parameters. Oncol Rep 2002, 9:409-416.

24. Dickson C, Fantl V, Gillett C, Brookes S, Bartek J, Smith R, Fisher C, Barnes D, Peters G: Amplification of chromosome band $11 \mathrm{q} 13$ and a role for cyclin $D_{1}$ in human breast cancer. Cancer Lett 1995, 90:43-50.

25. Buckley MF, Sweeney KJ, Hamilton JA, Sini RL, Manning DL, Nicholson RI, deFazio A, Watts CK, Musgrove EA, Sutherland RL: Expression and amplification of cyclin genes in human breast cancer. Oncogene 1993, 8:2127-2133.

26. Bieche I, Olivi M, Nogues C, Vidaud M, Lidereau R: Prognostic value of CCND1 gene status in sporadic breast tumours, as determined by realtime quantitative PCR assays. Br J Cancer 2002, 86:580-586.

27. Clarke R, Leonessa F, Welch JN, Skaar TC: Cellular and molecular pharmacology of antiestrogen action and resistance. Pharmacol Rev 2001, 53:25-71.

28. Zwart W, Rondaii M, Jalink K, Sharp ZD, Mancini MA, Neefjes J, Michalides R Resistance to antiestrogen arzoxifene is mediated by overexpression of cyclin $\mathrm{D}_{1}$. Mol Endocrinol 2009, 23:1335-1345.

29. Le Goff P, Montano MM, Schodin DJ, Katzenellenbogen BS: Phosphorylation of the human estrogen receptor. Identification of hormone-regulated sites and examination of their influence on transcriptional activity. J Biol Chem 1994, 269:4458-4466.

30. Kato $S$, Endoh $H$, Masuhiro $Y$, Kitamoto T, Uchiyama S, Sasaki $H$, Masushige S, Gotoh Y, Nishida E, Kawashima H, Metzger D, Chambon P: Activation of the estrogen receptor through phosphorylation by mitogen-activated protein kinase. Science 1995, 270:1491-1494.

31. Pietras RJ, Arboleda J, Reese DM, Wongvipat N, Pegram MD, Ramos L, Gorman CM, Parker MG, Sliwkowski MX, Slamon DJ: HER-2 tyrosine kinase pathway targets estrogen receptor and promotes hormone-independent growth in human breast cancer cells. Oncogene 1995, 10:2435-2446.

32. Holm C, Rayala S, Jirstrom K, Stal O, Kumar R, Landberg G: Association between Pak1 expression and subcellular localization and tamoxifen resistance in breast cancer patients. J Natl Cancer Inst 2006, 98:671-680.
33. Zwijsen RM, Wientjens E, Klompmaker R, van der Sman J, Bernards R, Michalides RJ: CDK-independent activation of estrogen receptor by cyclin $D_{1}$. Cell 1997, 88:405-415

34. Zwijsen RM, Buckle RS, Hijmans EM, Loomans CJ, Bernards R: Ligandindependent recruitment of steroid receptor coactivators to estrogen receptor by cyclin $D_{1}$. Genes Dev 1998, 12:3488-3498.

35. Wilcken NR, Prall OW, Musgrove EA, Sutherland RL: Inducible overexpression of cyclin $D_{1}$ in breast cancer cells reverses the growthinhibitory effects of antiestrogens. Clin Cancer Res 1997, 3:849-854.

36. Jirstrom K, Stendahl M, Ryden L, Kronblad A, Bendahl PO, Stal O, Landberg G: Adverse effect of adjuvant tamoxifen in premenopausal breast cancer with cyclin $D_{1}$ gene amplification. Cancer Res 2005, 65:8009-8016.

37. Dowsett M, Allred C, Knox J, Quinn E, Salter J, Wale C, Cuzick J, Houghton J, Williams N, Mallon E, Bishop H, Ellis I, Larsimont D, Sasano H, Carder P, Cussac AL, Knox F, Speirs V, Forbes J, Buzdar A: Relationship between quantitative estrogen and progesterone receptor expression and human epidermal growth factor receptor 2 (HER-2) status with recurrence in the Arimidex, Tamoxifen, Alone or in Combination trial. J Clin Oncol 2008, 26:1059-1065.

38. Harvey JM, Clark GM, Osborne CK, Allred DC: Estrogen receptor status by immunohistochemistry is superior to the ligand-binding assay for predicting response to adjuvant endocrine therapy in breast cancer. $J$ Clin Oncol 1999, 17:1474-1481.

39. McShane LM, Altman DG, Sauerbrei W, Taube SE, Gion M, Clark GM: Reporting recommendations for tumor marker prognostic studies (REMARK). J Natl Cancer Inst 2005, 97:1180-1184.

40. Arnould L, Denoux Y, MacGrogan G, Penault-Llorca F, Fiche M, Treilleux I, Mathieu MC, Vincent-Salomon A, Vilain MO, Couturier J: Agreement between chromogenic in situ hybridisation (CISH) and FISH in the determination of HER2 status in breast cancer. Br J Cancer 2003, 88:1587-1591.

41. Cuzick J: A Wilcoxon-type test for trend. Stat Med 1985, 4:87-90.

42. Dowsett M, Cuzick J, Wale C, Forbes J, Mallon EA, Salter J, Quinn E, Dunbier A, Baum M, Buzdar A, Howell A, Bugarini R, Baehner FL, Shak S: Prediction of risk of distant recurrence using the 21-gene recurrence score in node-negative and node-positive postmenopausal patients with breast cancer treated with anastrozole or tamoxifen: a TransATAC study. J Clin Oncol 28:1829-1834.

43. Camp RL, Dolled-Filhart M, King BL, Rimm DL: Quantitative analysis of breast cancer tissue microarrays shows that both high and normal levels of HER2 expression are associated with poor outcome. Cancer Res 2003, 63:1445-1448.

44. Weinstat-Saslow D, Merino MJ, Manrow RE, Lawrence JA, Bluth RF, Wittenbel KD, Simpson JF, Page DL, Steeg PS: Overexpression of cyclin D mRNA distinguishes invasive and in situ breast carcinomas from nonmalignant lesions. Nat Med 1995, 1:1257-1260.

45. Zukerberg LR, Yang WI, Gadd M, Thor AD, Koerner FC, Schmidt EV, Arnold A: Cyclin $D_{1}$ (PRAD1) protein expression in breast cancer: approximately one-third of infiltrating mammary carcinomas show overexpression of the cyclin $D_{1}$ oncogene. Mod Pathol 1995, 8:560-567.

46. Rudas M, Lehnert M, Huynh A, Jakesz R, Singer C, Lax S, Schippinger W, Dietze O, Greil R, Stiglbauer W, Kwasny W, Grill R, Stierer M, Gnant MF, Filipits M: Cyclin $D_{1}$ expression in breast cancer patients receiving adjuvant tamoxifen-based therapy. Clin Cancer Res 2008, 14:1767-1774.

47. Lehn S, Tobin NP, Berglund P, Nilsson K, Sims AH, Jirstrom K, Harkonen $\mathrm{P}$, Lamb R, Landberg G: Down-regulation of the oncogene cyclin $D_{1}$ increases migratory capacity in breast cancer and is linked to unfavorable prognostic features. Am J Pathol 2010, 177:2886-2897.

doi:10.1186/bcr3161

Cite this article as: Lundgren et al: Effects of cyclin $\mathrm{D}_{1}$ gene

amplification and protein expression on time to recurrence in postmenopausal breast cancer patients treated with anastrozole or tamoxifen: a TransATAC study. Breast Cancer Research 2012 14:R57. 